\title{
A oralidade na escola: \\ um (longo) percurso a ser trilhado
}

The orality in the school: a long way to be covered.

Gil Negreiros

Universidade Federal de Santa Maria (UFSM), Santa Maria, RS, Brasil

Gislaine Vilas Boas

Instituto Federal Farroupilha (IF - Farroupilha), Farroupilha, RS, Brasil

Resumo: No âmbito educacional brasileiro, torna-se essencial à escola a formação de sujeitos bem articulados com a língua, seja na modalidade escrita, seja na modalidade oral. Nesse sentido, busca-se, a partir desta reflexão científica, uma ressignificação do trabalho docente no que tange às práticas desenvolvidas com a oralidade na escola. Por isso, os objetivos deste artigo são discutir as necessidades sócio-políticas necessárias para um ensino qualitativo, baseado em uma vertente textual, discursiva e interacional, de oralidade no âmbito das aulas de língua portuguesa, além de apresentar algumas competências docentes que devem ser aprimoradas e que podem garantir maior segurança e assertividade no tratamento da oralidade na escola.

Palavras-chave: Oralidade. Gêneros orais públicos. Práticas de ensino. Formação docente.

Abstract: In the brazilian educational context, it becomes essential to the school the formation of well-articulated students with the language, either in the written modality or in the oral modality. In this sense, it is sought, from this scientific reflection, a resignification of the teaching work regarding the practices developed with orality in the school. Therefore, the aim of this article is to propose an awareness of the oral language importance in the school environment, as well as to propose new methodologies so that the teacher can carry out a fruitful work with orality under a new posture in face of the variety of uses of oral language.

Key-words: Orality. Public oral genres. Teaching practices. Teacher training.

\section{Introdução}

É certo afirmar, como já postula Marcuschi (1997), que é fundamental

o trabalho com oralidade nas aulas de língua materna. Contudo, esse 
Gil Negreiros

Gislaine

Vilas Boas

tópico amiúde tem sido deixado de lado pela comunidade escolar, em virtude do foco que ainda é dado às aulas de português, cuja função precípua, acredita-se, seja apenas ensinar a escrever e a escrever bem, apesar das muitas contribuições oferecidas hoje pelo desenvolvimento das ciências da linguagem (como a Análise da Conversação, a Análise do Discurso, a Linguística Textual e a Sociolinguística Interacional).

Nesse sentido, este artigo tem como objetivo discutir as necessidades sócio-políticas necessárias para um ensino qualitativo de oralidade, baseado em uma vertente textual, discursiva e interacional, no âmbito das aulas de língua portuguesa. Além disso, buscamos também apresentar algumas competências docentes que, a nosso ver, devem ser aprimoradas e que garantiriam maior segurança e assertividade no tratamento da oralidade na escola.

Ao longo do texto, buscamos mostrar que a melhoria qualitativa do ensino de língua portuguesa passa, sem desconsiderar outros fatores, pela eficácia do trato das questões orais. E tal eficácia só é possível com uma mudança na formação docente e com o comprometimento das instituições de ensino em aliar saberes acadêmico-científicos às práticas escolares. Em outros termos: acreditamos na necessidade de uma mudança de postura: aulas significativas, com objetivos claros, bem preparadas e bem ministradas, realizadas por profissionais bem formados e conscientes do trabalho docente.

Parece-nos necessário, pois, no âmbito das políticas públicas de ensino de língua portuguesa, sérias reflexões sobre a prática de ensino de língua materna em sua modalidade oral, bem como a criação de alternativas linguístico-educacionais para o ensino da oralidade.

\section{Por que trabalhar com oralidade?}

No âmbito educacional brasileiro, urge a escola formar sujeitos bem articulados com a língua, seja na modalidade escrita, seja na modalidade oral. Especificamente, os usos heterogêneos pertencentes à modalidade oral, principalmente os "usos formais públicos", aqueles que os falantes não aprendem em situações mais distensas e informais, devem ser objeto de preocupação das aulas de língua.

Para o aluno, saber argumentar, narrar e expor, reconhecendo a situação interacional em que está exposto, pode ser o primeiro passo para se tornar um sujeito-falante fora da margem social, um "falante desmarginalizado". E parece-nos que esse é o papel da escola moderna: 
Evidentemente, para um jovem que vai disputar pela primeira vez um emprego, há implicações de toda ordem, inclusive de natureza linguística. E não se trata de um caso isolado. Preparar o aluno para isso é ensino contemporâneo, atualizado e comprometido com a realidade. (CRESCITELLI; REIS, 2011, p 36)

Para o professor, o trabalho com a oralidade, de forma efetiva e em consonância com fundamentos de ordem linguística e não gramatical, pode ressignificar o trabalho docente no ensino de língua materna. Além, é claro, de atender a uma parte do previsto na LDB, segundo a qual o texto - oral e escrito - deve ser a unidade básica para o ensino de língua materna e a atividade de ensino da língua deve concentrar-se na produção de textos orais e escritos em seus mais diversos aspectos e gêneros (cf. BRASIL, 1998, p. 33).

A oralidade na escola

A escola, assim, é o contexto interacional que deve "concorrer para que o aluno seja um usuário linguístico competente, capaz de adequar a língua em instância pública dialógica diversificada e complexa a qual envolve inúmeras situações do exercício da cidadania a avaliações." (CRESCITELLI; REIS, 2011, p. 32)

Bentes (2011, p. 46-7), ao se referir às práticas sociais do interior da escola brasileira, que deveria ser verdadeiramente uma organização democrática, destaca que parecem "carecer de reciprocidade, sinceridade, interesse público, emoção, sensibilidade e de uma comunicação mais genuína e racional".

Segundo a autora, todos esses problemas vividos pela escola revelam que a "nossa luta, hoje, no campo da educação, não é mais pela fundamentação dos direitos humanos, mas por sua proteção e implementação." Nesse sentido, as práticas de oralidade na escola se inserem em um quadro de grandes dificuldades de implementação de práticas educativas que "levem as pessoas a serem mais solidárias, tolerantes, sem, no entanto, perder a capacidade crítica e de indignação com relação às injustiças sociais." (2011, p. 46-7).

\section{0 ensino de oralidade:}

\section{uma questão já muito falada, mas...}

Há no mínimo três décadas que oralidade e fala (bem como as relações existentes entre esses dois fenômenos com letramento e escrita ${ }^{1}$, respectivamente) vêm sendo discutidos por pesquisadores de diversas áreas

1 Baseamo-nos em Marcuschi (2001, p. 25-6) quando usamos essa terminologia. 
Gil Negreiros

Gislaine

Vilas Boas

de estudo, como linguistas, pedagogos, sociólogos, psicólogos e assistentes sociais, por exemplo. Tais temas, vinculados à ordem da linguagem e da interação social, constantemente tornam-se objetos de estudo a partir de experiências e reflexões advindas dos mais diferentes centros acadêmicos do Brasil e do exterior.

Talvez seguindo essa tendência, os PCNs, mesmo que de forma vaga e sem discutir alternativas de trabalho pedagógico sobre o tema, afirmam que a oralidade deve ser tratada de forma prioritária no ensino de língua portuguesa ${ }^{2}$. Segundo o documento, o português brasileiro possui muitos dialetos e falares regionais; também destaca a questão do preconceito por parte de parcela de falantes com as variedades de menor prestígio social:

a questão não é falar certo ou errado e sim saber que forma de fala utilizar, considerando as características do contexto de comunicação, ou seja, saber adequar o registro às diferentes situações comunicativas. É saber coordenar satisfatoriamente o que falar e como fazê-lo considerando a quem e por que se diz determinada coisa. (PCNs, 1996, p. 16)

Nesse aspecto, ainda que se note certo caráter generalista dado pelos Parâmetros Curriculares Nacionais à questão da oralidade se considerarmos a questão da "adequação às circunstâncias de uso" (Ibidem, p. 15), é possível perceber que o assunto é abordado como uma tentativa de sinalização metodológica. Desta forma, mesmo com as adiantadas discussões acadêmicas sobre a oralidade e com a presença, ainda que defeituosa, do tema nos PCNs, o que se percebe é ainda um significativo distanciamento das atividades escolares com a prática oral ${ }^{3}$.

Alguns pontos podem ser apresentados para se explicar esse distanciamento. 0 primeiro deles se refere à crença, ainda fortemente arraigada nas comunidades escolares, de que a função da escola seja, apenas, ensinar a escrita. A valorização extrema do texto escrito é, nesse sentido, mais do que atividades, mas uma postura de trabalho.

2 Não é nosso intuito, neste artigo, discutir os problemas apresentados nos PCNs sobre a questão da oralidade. Como aprofundamento em discussões desse tipo, consultar Marcuschi (1997), Crescitelli e Reis (2011).

3 Não queremos dizer aqui que não há iniciativas pontuais que trabalhem de forma correta o tema no contexto educacional brasileiro. Concordamos com Bentes (2011, p. 47) de que "essas iniciativas são exceções e não têm conseguido se transformar em práticas consistentes e generalizadas." 
Marcuschi afirma que, talvez pela ideia ingênua de que não seja necessário trabalhar com oralidade com os alunos, já que chegam à escola sabendo conversar, a escola brasileira adota uma postura segundo a qual a escola é o lugar do aprendizado da escrita. Segundo o autor, é possível concordar com a ideia de que se deve ensinar o texto escrito, «mas é possível também acrescentar que nem por isso a escola está autorizada a ignorar a fala. $\mathrm{O}$ homem é tipicamente um ser que fala $\mathrm{e}$ não um ser que escreve» (cf. 2007, p. 39)

A esse respeito, Castilho também pondera, corroborando com Marcuschi:

A oralidade

na escola

É evidente que não estou propondo a exclusão da língua escrita. Simplesmente estou propondo que a escola imite a vida: primeiro aprendemos a falar, depois aprendemos a escrever. Que nas reflexões escolares sobre nossa língua, acompanhemos esse ritmo, deixando de lado uma tola supervalorização do escrito sobre o oral. $(2000$, p. 67$)$

Como bem apontam Dolz \& Schneuwly (2004), na escola, a oralidade é tratada, muitas vezes, de forma reducionista: ou é relacionada ao "falar cotidiano" ou à leitura e declamações do texto escrito. Assim, por um lado, seria inútil ensinar algo ao aluno que ele já domina e, por outro, a questão é trabalhada, apenas, como uma "oralização da escrita" (prática que, de certa maneira, também denuncia a valorização extrema da escrita).

O segundo ponto relaciona-se à formação docente deficitária, que distancia os novos docentes de uma formação linguística sólida, o que dificulta, e muito, o estabelecimento de uma nova relação com a linguagem por parte do professor. Some-se a isso o fato de que o trabalho com o texto oral necessita de um olhar especial por parte do profissional que dê conta das especificidades do corpus.

Bentes (2010, p. 132) aponta algumas complexidades do texto oral que devem ser dominadas pelo docente. O fato de que a fala "é emoldurada tanto pela maneira como são pronunciados determinados sons (segmentos) como também pela maneira como o fluxo da fala (suprassegmentos) é produzido (o que envolve pausas, entoação, qualidade de voz, ritmo e velocidade da fala)" são itens muito relevantes para dar um tratamento adequado ao assunto. 
Gil Negreiros

Gislaine

Vilas Boas

Além disso, torna-se fundamental a percepção de que estamos em contato com um conjunto de linguagens "que coocorrem ao mesmo tempo em que falamos: a gestualidade, a postura corporal, a expressão facial e o direcionamento do olhar." (IBIDEM, p. 134)

A autora postula que, quando se considera as especificidades da oralidade, o profissional adota uma nova postura frente à questão, o que pode levá-lo a uma nova postura frente à linguagem:

A consideração destas outras linguagens leva a uma compreensão da oralidade que ultrapassa, mais uma vez, a visão de que esta é apenas um conjunto de práticas que tem por objetivo maior a transmissão de informações pelo meio sonoro. Considerar a oralidade é, muitas vezes, necessariamente, considerar a percepção visual que se tem do outro e que o outro tem de nós. (IBIDEM, p. 134)

Parece-nos que, nesse sentido, a autora vai ao encontro dos postulados de Dolz, Schneuwly e Haller, segundo os quais "tomar a palavra encontra-se em íntima relação com corpo" (2004, p. 159). Assim, o primeiro passo para o docente realizar um trabalho profícuo com a oralidade passa pela adoção de uma nova postura frente à variedade dos usos da linguagem oral.

O trabalho com oralidade ${ }^{4}$ deve se embasar no fato de que toda produção discursiva se apoia em diferentes níveis de significação, em um caráter multissemiótico, para além dos recursos meramente linguísticos, ou seja, “os processos de produção e de recepção dos discursos e textos (orais e escritos) envolvem necessariamente a mobilização, por parte do produtor do e/ou receptor, sonoridades, visualidades, movimentos, texturas etc." (BENTES, 2010 p. 131)

Como assevera Leite, essa percepção requer do observador uma visão holística do fenômeno oral:

\footnotetext{
o tratamento da oralidade exige do analista não somente manejo de dados como também perspicácia para a compreensão da situação discursiva que envolve os interactantes. Tal expressão, na realidade, é um "baú" que abriga aspectos psicológicos, sociais, cognitivos e culturais de todos os envolvidos nas intera-
}

4 Não só as produções discursivas orais, mas também as produções discursivas escritas. 
ções; por isso, o dado provindo de situações de oralidade deve ser examinado a partir de uma visão de $360^{\circ}$ que capte, com base no que é visível e audível, tudo o que é inerente à interação, não somente o posto, pressuposto e subtendido, mas também o que condiciona formas, conteúdos e propicia a estabilidade, ou instabilidade, da interação. (LEITE, 2012, P. 2017)

Como afirmam Rojo e Schneuwly (2006, p. 463), não há “o oral”, mas sim "os orais" sob diversas formas, de maneira heterogênea. Assim, não existe uma "essência mítica" do oral, que poderia fundar sua didática, nos dizeres de Dolz \& Schneuwly, mas sim práticas de linguagem específicas, que ocorrem em ambientes determinantes da interação, que podem se tornar objeto do estudo escolar. Tais práticas, segundo A oralidade na escola os autores, tomam, necessariamente, as formas mais ou menos estáveis que denominamos gêneros ${ }^{5}$.

Nessa perspectiva, enquanto o texto é visto como objeto concreto e empírico, sobre os quais o trabalho em sala de aula deve acontecer, o gênero define a unidade de trabalho que articula esses objetos. (cf. 2004, p. 133-44).

Dolz e Schneuwly (2004, p. 64) partem, assim, da hipótese de que é por meio das representações do gênero e pelo seu caráter integrador que as práticas de linguagem se materializam nas atividades de produção oral e escrita, constituindo-se uma fundamental ferramenta didática. A aprendizagem linguística, para os pesquisadores, aconteceria na relação entre práticas e atividades de linguagem:

Nesse lugar [espaço situado entre as práticas e as atividades de linguagem], produzem-se as transformações sucessivas da atividade do aprendiz, que conduzem à construção das práticas de linguagem. Os gêneros textuais, por seu caráter genérico, são um termo da referência intermediário da aprendizagem. Do ponto de vista do uso e da aprendizagem, o gênero pode, assim, ser considerado um megainstrumento que fornece um suporte para a atividade, nas situações de comunicação, e uma referência para os aprendizes. ( DOLZ; SCHNEUWLY, 2004, p. 64-5)

5 Sobre a questão dos gêneros, parece-nos que os autores têm, como base, as ideias de Bakhtin (2000, p. 279-80), sobre gêneros. 
Gil Negreiros

Gislaine

Vilas Boas

Cabe lembrar que as ideias sobre ensino de gêneros orais públicos coordenadas pelo grupo de Dolz e Schneuwly são significativas não só por apresentar reflexões teóricas sobre o tema, mas sobretudo por trazer a público a proposta de ensino denominada de "sequência didática". Dolz, Noverraz e Schneuwly apresentam essa proposta, composta por um conjunto de atividades didáticas, organizadas e sistematizadas, que se ocupam de um gênero textual oral (ou escrito). 0 trabalho seria realizado, efetivamente, a partir de gêneros públicos, não dominados pelos alunos. (cf. IDEM, 2004, p. 82-3)

\section{A oralidade no ensino: o caminho ainda a ser trilhado}

A partir dos postulados supracitados, pensamos que o professor deve ultrapassar o lugar de repetidor de fórmulas antigas, alcançando uma posição de pesquisador e analista da linguagem oral frente à situação discursiva em que os interactantes estão envolvidos.

Tal mudança de postura, obviamente, não é algo simples, e se ancora na adoção de políticas docentes amplas e gerais, que possam privilegiar qualitativamente o cenário do sistema educacional. Como exemplo de medidas, podemos citar, sem esgotamento das propostas:

a) Revisão das bases curriculares dos cursos de licenciatura em Letras do país, aliando os conhecimentos científicos da universidade com a prática. É um engano a velha máxima ainda muitas vezes cultuada segundo a qual "as teorias não possam se aliar às questões práticas”. Não há dicotomia entre conhecimento teórico e prático.

b) Definições de didáticas específicas de ensino de língua materna para problemas específicos. A grosso modo, frente a um problema didático, o que um professor precisa fazer para resolvê-lo? Quais as estratégias precisam ser adotadas?

c) Valorização das vocações de futuros docentes de língua materna, com incentivos de várias ordens para que os alunos interessados tornem-se professores.

d) Incentivo à qualificação (formação continuada) dos professores de língua materna, em intercâmbio com as universidades.

e) Renovação do material didático usado nas aulas de língua materna, com propostas equânimes que envolvam tanto a modalidade escrita como a oral. 
Finalizamos o item anterior deste artigo apresentando aspectos que, a nosso ver, seriam imprescindíveis para uma melhoria significativa no ensino de oralidade no âmbito do ensino básico brasileiro. 0 que buscamos reforçar, nessa discussão, é que, diante das necessidades sociais de nosso tempo, o trabalho com aspectos de oralidade nas aulas de língua portuguesa certamente será mais fácil se feito por um profissional bem formado e valorizado, consciente dos problemas da contemporaneidade e em sintonia com o desenvolvimento técnico-científico de sua área de atuação. Tal profissional conseguirá atuar com clareza e segurança frente aos desafios a ele apresentados.

A oralidade

Assim, uma postura textual, discursiva e interacional da oralidade, condizente com questões contemporâneas, poderia ser adotada pelo docente. Tal postura, por exemplo, seria marcada pelas seguintes competências:

a) Capacidade de adoção de princípios teórico-metodológicos a serem seguidos na preparação de aulas de oralidade.

b) Conhecimento textual, discursivo e interacional de práticas/gêneros textuais orais ${ }^{6}$ que possam ser trabalhados com determinada turma.

c) Cumprimento de metas a serem obtidas no trabalho com gêneros orais na escola.

d) Montagem de materiais didáticos que sejam adequados ao trabalho com prática/gênero oral.

e) Aplicação de metodologias, como a proposta das "sequências didáticas", que sejam adequadas ao trabalho com o gênero escolhido.

f) Percepção dos riscos e dos ganhos de se trabalhar sob determinada perspectiva metodológica.

g) Elaboração de projetos interdisciplinares em que se trabalhe a questão da oralidade.

h) Definição de avaliações a respeito do gênero oral trabalhado, centradas nos aspectos linguísticos, extralinguísticos e paralinguísticos.

i) Estabelecimento de gêneros orais públicos com outros gêneros orais ou escritos, a partir de uma ideia noção de "sistema de gêneros".

j) Domínio de tecnologias que funcionam como suporte para os diversos gêneros orais a serem trabalhados.

6 Para uma definição precisa de gênero oral, consultar Travaglia (2013). 
Obviamente, essa listagem não é exaustiva e poderia ser completada com outras competências significativas a serem desenvolvidas na vida profissional do docente no que tange ao trabalho com oralidade. Contudo, os tópicos citados são fundamentais para se pensar uma nova maneira de tratamento do tema.

\section{Considerações finais}

Gil Negreiros

Gislaine

Vilas Boas

Podemos, neste artigo, discutir um pouco sobre a questão de se trabalhar com a oralidade no ensino. A necessidade de se buscar a adoção de tais práticas nas aulas de língua portuguesa é evidente e urgente. É evidente, pois, há tempos, o ensino de oralidade ser figura como uma obrigação, haja vista a presença desse dever na legislação do país; é urgente, pois a qualificação dos alunos em práticas linguísticas significativas é um dos caminhos da desmarginalização social.

Nesse sentido, parece-nos que a questão a ser discutida não é o "ponto de chegada", mas sim os passos que precisamos dar para se chegar nesse ponto. E todos os passos não escapam da figura do profissional em educação: o professor. É ele que deve atuar clinicamente no processo, definindo metodologias e aplicando seus conhecimentos teóricos em práticas de ensino eficazes.

Deste modo, formar bem os professores (da mesma maneira como é importante formar bem todos os outros profissionais, como médicos, engenheiros, advogados) e adotar políticas públicas de valorização profissional são fundamentais.

É fato que nossas universidades possuem amplas pesquisas educacionais (de impacto e de mensuração) que abordam mudanças no paradigma didático, além de haver casos isolados de novas metodologias de trabalho docente em diversas escolas. Tais exemplos de sucesso são evidências de que é possível novos cenários educacionais.

Há que se buscar metas e há que se cumpri-las; há que se ter definição de papéis, de compromissos. Há que se adotar inovações. Para se ter, de fato, avanços no ensino, há que se ter obsessão por mudanças qualitativas. 


\section{REFERÊNCIAS}

BAKHTIN, Mikhail. Estética da Criação Verbal. 3. ed. São Paulo: Martins Fontes, 2000.

BENTES, Anna Christina. Linguagem oral no espaço escolar: rediscutindo o lugar das práticas e dos gêneros orais na escola. In: RANGEL, E. G.; ROJO, R. Língua Portuguesa. Coleção Explorando o Ensino. Brasília - MEC, v. 19, pp. 129-154, 2010.

A oralidade - Oralidade, política e direitos humanos. In: ELIAS, V. M. Ensino de língua portuguesa: oralidade, escrita, ensino. São Paulo: Contexto, 2011.pp. 41-54.

BRASIL. Parâmetros Curriculares Nacionais - terceiro e quarto ciclos do ensino fundamental: língua portuguesa (PCNEF) Brasília: Ministério da Educação, Secretaria de Educação Fundamental, 1998.

CASTILHO, Ataliba T. de. Seria a língua falada mais pobre que a escrita? Impulso, v. 12, n. 27, pp. 59-72, 2000. Disponível em https:// blog.lusofonias.net/?p=4516. Acesso em 27 março 2017 .

CRESCITELLI, Mercedes Canha; REIS, Amália Salazar. O ingresso do texto oral em sala de aula. In: ELIAS, V. M. Ensino de língua portuguesa: oralidade, escrita, ensino. São Paulo: Contexto, 2011. pp. 29-40.

DOLZ, Joaquim; SCHNEUWLY, Bernard. Gêneros orais e escritos na escola. Campinas-SP: Mercado de Letras, 2004.

DOLZ, Joaquim; SCHNEUWLY, Bernard; NOVERRAZ, Michèle. Sequências didáticas para o oral e escrita: apresentação de um procedimento. In: SCHENEUWLY, B.; DOLZ, J. Gêneros orais e escritos na escola. Campinas-SP: Mercado de Letras, 2004. pp. 95-128.

DOLZ, Joaquim; SCHNEUWLY, Bernard.; HALLER, Sylvie. O oral como texto: como construir um objeto de ensino. In: SCHENEUWLY, B.; DOLZ, J. Gêneros orais e escritos na escola. Campinas-SP: Mercado de Letras, 2004. pp. 149-188. 
LEITE, Marli Quadros. Interação, texto falado e discurso. In: BRAIT, B.; SOUSA-E-SILVA, M. C. Texto ou discurso? São Paulo: Contexto, 2012. pp.217-236.

MARCUSCHI, Luiz Antônio. Concepção de língua falada nos manuais de português de $1 .^{\circ}$ e $2 .^{\circ}$ graus: uma visão crítica. In: Trabalhos de Linguística Aplicada. Campinas-SP, n. 30, pp. 39-79. jul-dez. 1997.

Gil Negreiros

Gislaine

Da fala para a escrita: atividades de retextualização. São

Vilas Boas

Gêneros textuais: definições e funcionalidade. In.: DIONISIO, Angela Paiva; MACHADO, Anna Rachel; BEZERRA, Maria Auxiliadora. Gêneros textuais e ensino. 5. ed. Rio de Janeiro: Lucerna, 2007.

ROJO, Roxane; SCHNEUWLY, Bernard. As relações oral/escrita nos gêneros orais formais e públicos: o caso da conferência acadêmica. In: Linguagem e (dis)curso - LemD. Tubarão-SC, v. 6. n. 3, p. 463493, set./dez. 2006.

TRAVAGLIA, Luiz Carlos et al. Gêneros orais - conceitos e caracterização. Anais do SILEL. v. 3. n. 1. Uberlândia: EDUFU, 2013.

Recebido em 06 de março de 2017. Aceito em 05 de maio de 2017. 